\title{
SOCIAL AND TECHNOLOGICAL ASPECTS OF DISASTER RESILIENCE
}

\author{
Luisa GIULIANI ${ }^{a, *}$, Alexandra REVEZ ${ }^{\text {b }}$, Jörgen SPARF ${ }^{\text {e }}$, Suranga JAYASENA ${ }^{\text {d, }}$ \\ Michael Havbro FABER a \\ ${ }^{a}$ Civil Engineering Department, Technical University of Denmark, Lyngby, Denmark \\ ${ }^{b}$ Department of Geography, National University of Ireland - Galway, Galway, Ireland \\ ${ }^{c}$ Department of Social Sciences, Risk and Crisis Research Center, Mid-Sweden University, Sundsvall, \\ Sweden \\ ${ }^{d}$ Department of Building Economics, University of Moratuwa, Columbus, Sri Lanka
}

Received 7 April 2015; accepted 24 August 2015

\begin{abstract}
Large scale projects tasked with designing infrastructures and urban networks resilient to disasters face a common challenge, i.e. the need to address concomitant technological issues and social problems. What is more, conflicting technologies and the diverse philosophical underpinnings of distinct academic disciplines pose difficulties in the collaboration among experts of different fields. These difficulties and possible ways to tackle them have been highlighted by a questionnaire developed in the framework of an EU project named ANDROID (Academic Network for Disaster Resilience to Optimize Educational Development). More specifically, the project investigated the level of interdisciplinary work in current research and educational projects within the field of disaster resilience. Findings illustrate the number and types of disciplines involved in disaster resilience projects and suggest that a higher degree of integration between different disciplines in tertiary education could promote a transdisciplinary approach to disaster resilience, resulting in design efficiency and innovation.
\end{abstract}

KEYWORDS: Disaster resilience; ANDROID project; Interdisciplinary; Transdisciplinary; Education

\section{INTRODUCTION}

Disaster resilience, intended as the ability of a system to bounce back to original performances after being hit by a natural or man-made hazard event (for a more precise definition of the terms reference is made to the following section), is a fundamental property of modern built environments.

The topic is recently gaining the attention of the society for a twofold reason: on one side, the frequency of accidental events of both natural and man-made origin seems to have increased in the last two decades (EEA 2010); on the other side, the domino effect shown by some accidents (Pescaroli, David 2015) has highlighted how even events with a very low probability of occurrence may lead to major disasters. The second aspect is particularly relevant from a design point of view, as very low probability events are often disregarded in current design practice for buildings and infrastructures. This over-simplification is clearly not possible, if

\footnotetext{
* Corresponding author. E-mail: lugi@byg.dtu.dk
}

a disaster resilient design of urban areas is to be achieved. In this case, more advanced design approaches must be followed, where the consequences of an initial accident on neighbour areas and systems are investigated (Ortensi et al. 2013). Such large-scale disaster management (JCSS 2008) requires understanding and modelling the response and interactions of different technological systems (such as the transportation system, the supply system, the communication systems, etc.) as well as of societal systems (such as administrations, regulations and policies, financial mechanisms, etc.). The latter implies the prediction of human behaviour and community response to emergencies, which determines a greater level of uncertainty in the problem. It also creates a further element of complexity, given that the behaviour of technological and social systems is often tightly coupled.

Even if a systemic study of disasters has been undertaken by researchers since the seventies (Haas et al. 1977), the formulation of a framework 
for disaster resilience design is quite recent (Gilbert 2010) and only few quantitative definitions of disaster resilience have been attempted (Bruneau et al. 2003; Chang, Shinozuka 2004). Furthermore, despite the crucial role of individuals and communities having been recently highlighted by researchers (Keck, Sakdalpolrak 2013), the consideration of societal issues in disaster resilience design is often limited or not accurate.

A brief state of the art concerning the definition of disaster resilience and the consideration of its social aspects is presented in the second section of this paper. The multidisciplinary character of resilience is also highlighted and different levels of interdisciplinary work, as reported in literature, are presented. It is argued that the co-existence of so many and different disciplines may impair progresses and innovation in the area of disaster resilience, which, despite an increasing attention and support from the authorities, has not yet achieved significant advances in the design practice. For this reason, a survey has been implemented, aimed at identifying the major obstacles to interdisciplinary work and get some insights on the causes and possible solutions to the problems. The implementation of the survey has been conducted in the framework of the Academic Network for Disaster Resilience to Optimize Educational Development (ANDROID 2011), a project funded by the Lifelong Learning Programme of the European Union and aimed at promoting co-operation and innovation among European Higher Education Institutions (HEIs) for increasing the disaster resilience of urban communities. The implementation of the survey is presented in section 3, while the outcomes of the survey are discussed in section 4 . Some final considerations on good practice in education and research are given in the conclusions.

\section{DISASTER RESILIENCE}

\subsection{Definition}

Various propositions for the definition of the term resilience can be found in the literature (Bhamra et al. 2011) pertaining to the different fields where this concept has been used, which space from engineering (Hollnagel et al. 2006), to economy (Hamel, Valikangas 2003) and management (Sheffi 2005), ecology and sociology (Walker et al. 2004), and psychology (Bonanno et al. 2007). Although mostly based on the concept of a good response to a critical event, they differentiate for focusing either on the capacity of a system to absorb the effects of a shock or to promptly recover from it. Some authors also mention the ability to anticipate and prevent the adversities (UNDP 2013) as well as learning by them (Cadell et al. 2001). However, these definitions are mostly qualitative and hardly quantitative and do not clearly identify the system in terms of space, time, and stakeholders.

One of the first consistent and quantitative definitions of disaster resilience has been developed at the Multidisciplinary Center for Earthquake Engineering Research (MCEER) with respect to the built-environment. In the MCEER framework, resilience is defined as the ability of a system to mitigate hazards and consequences of hazards, in terms of loss of performances of the system and time needed for a full recovery of the initial performances (Bruneau et al. 2003). According to this definition, the resilience of a system can be quantitatively assessed by diagramming the variation of a relevant quality of the system over time.

This is schematically represented in the central part of Figure 1: at time $t_{0}$ an accidental event occurs and causes a drop in the original quality level of the system; then, the system undergoes reparation and is restored to the original quality level at time $t_{\mathrm{R}}$.

The entity of quality loss $\Delta \mathrm{Q}$ depends on the hazard, as well as on properties inherent to the system, such as: i) the ability to withstand the accidental event without being damaged; and ii) the ability to cope with local damages induced by the event by maintaining a sufficient level of functionality. In the MCEER resilience framework, the two system properties are referred to as robustness and redundancy, respectively. Being dependent on the initial area hit by the accident and to a possible spread of failures on adjacent areas and systems, these properties are related to the space factor of resilience (left side of Fig. 1).

It is worth noticing that the terms robustness and redundancy are not univocal and that, in general, disaster resilience properties suffers from a lack of consistent definitions in literature. For example, the term vulnerability is often used for indicating the immediate direct consequences of an accident on a system (Augusti et al. 2001; JCSS 2008), while the term robustness is often used with reference to the indirect consequences caused by a propagation of failures on adjacent systems (Faber 2006; Starrosek 2009; Biondini, Frangopol 2008).

The time factor of disaster resilience is accounted for by means of a recovery function and the time interval $\left(t_{\mathrm{R}}-t_{0}\right)$ needed to achieve full restoration. Aspects related to time-factor are mostly affected 


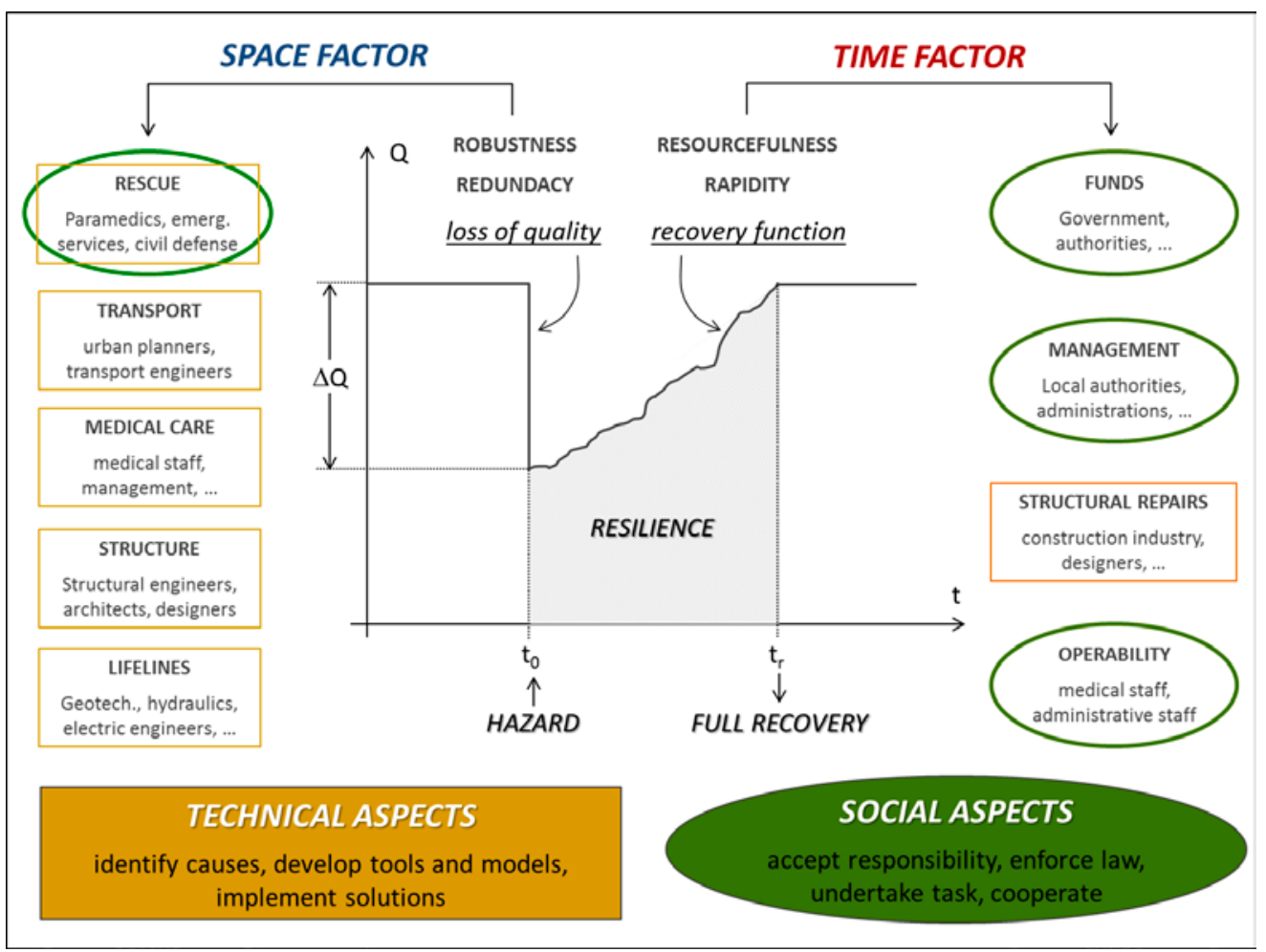

Fig. 1. Quantitative representation of resilience according to MCEER (central part) and examples of disciplines involved in the improvement of resilience properties of an acute medical care system in case of an earthquake (side boxes)

Note: The central part of the picture is adapted from Cimellaro et al. (2010). Permission from the authors has been obtained.

by social, economic, and political aspects. In the MCEER resilience framework the properties of resourcefulness and rapidity are referred to these aspects: the property of resourcefulness is related to the ability of establishing priorities and mobilizing the necessary monetary, technological, and informational resources; the property of rapidity is intended as the capacity to meet the established goals in a timely manner.

Even though both space and time factor are considered in this framework, the consideration of the time factor is limited to the aftermath of the accident. A more general time framework for risk management (JCSS 2008) identifies three different time situations, namely before, during, and after the hazard. Each situation refers to the optimization of investments in prevention, reduction, and recovery measures, respectively.

\subsection{Social aspects}

Even if the definition of resilience given above focuses primarily on technologic aspects, it is evident that the property of resourcefulness and rapidity defined in the MCEER framework are strongly affected by the socio-economic situations and by the human behaviour. In order to better address the role of community response in the assessment of disaster resilience, the same authors (Renschler et al. 2010) have been working on the development of a new resilience framework that better includes aspects related to Population, Environment, Organized governmental services, Physical infrastructure, Lifestyle and community, Economic development, and Social-cultural capital (PEOPLES). Further research (Norris et al. 2008) has also been addressed to introduce the effects of psychological distress on community individuals in the aftermath of disasters.

A recurrent image of the logics of catastrophes envisages a total breakdown of the social structures, which opens up for violence and looting. However, research has demonstrated that this is not likely to occur (Auf der Heide 2004; Quarantelli 1994) and, quite contrary to flourishing stories, people do not become hostile or misanthropic but rather helpful and caring during and after disasters (Rasmussen et al. 2013). The resilience of communities is dependent on social interaction and collective action based on networks of relationships, reciprocity, trust, and social norms. There are many theoretical models, which address 
this concept (Adger 2003; Paton, Johnston 2006). Most models focus on the issues that reduce the vulnerability of communities, such as information and knowledge, supportive networks, shared community values, and the community's ability and willingness to adapt. Lesser research focuses on how to increase disaster resilience by strengthening community capabilities.

The issue of increasing societal resilience, although being associated with different factors (Choularton 2001), is greatly related to the ability of learning from previous disasters (Pelling 2007; Rasmussen et al. 2013). The concrete utility of learning is that it improves the recovery from disrupting events (Chamlee-Wright 2010) and makes people and organizations better prepared, so the responses are to the point of departure in the next disaster. However, not only is the immediate learning important, but also long-term learning from inscriptions in local cultures play a central role, as memories from disasters may keep the experiences and knowledge alive over generations (Ullberg 2013).

\subsection{Interdisciplinary character}

From the MCEER definition of resilience and the additional social aspects discussed above, it is evident that the disciplines that need to be integrated in a resilience assessment are various and quite different.

In order to exemplify the interdisciplinary character of resilience, reference can be made to the response of the acute medical care facility system to an earthquake reported in Cimellaro et al. (2010) and exemplified in Figure 1. The performance drop of the care facility could be assessed, for example, by measuring the number of casualties due to inadequate health care capacity. From a design decision making perspective, the performance loss could be reduced by enhancing the resistance of hospitals to structural damages (robustness of the system, as defined in the MCEER framework), but also by increasing the number of hospitals or improving the capacity of redirecting patients from one hospital to another, so that the consequence of the shut-down of one hospital will be minimized (redundancy of the system, as defined in the MCEER framework).

The professional skills required to carry out such mitigation measures would be: i) structural engineers, architects, and interior designers for mitigating the physical damages to structure and facilities; ii) geotechnical engineers, hydraulic engi- neers, and electric engineers for ensuring the functionality of the lifelines that serve the hospitals iii) administrative and medical staff for handling the management of hospital facilities during the emergency; iv) paramedics, emergency services and civil defence for directing and coordinating rescue operation and optimal distribution of patients among the operative hospitals; v) urban planners, transport engineers, and network modellers for improving the existing transport infrastructures as well as ensuring a timely rescue of injured persons and their fast delivery to the health care facilities; vi) system engineers, computer scientists, and communication employees, for managing the information flow in an effective manner.

The restoration time will be instead determined by the time needed by: i) politicians, to allocate funds for the retrofitting of the hospital facilities and the infrastructures serving them; ii) construction industry, to carry out the structural repairs; iii) administration and medical staff in the hospital, to restore the medical activities and organize the repair operation in the premises; iv) local authorities, to direct and manage the restoration of the infrastructure in an effective and timely manner.

Even for a relatively small system such the one considered in this example, the number and distance of the fields involved in the assessment and design of the resilience of the system is extremely large. The identification of the main problems to face during such broad interdisciplinary working and the development of good practices aiming at solving them are therefore aspects of outmost importance within the framework of resilient design.

\subsection{Definition of interdisciplinary work}

The term "interdisciplinary" has been used above with the general meaning of the property of relating to more than one branch of knowledge. Branch of knowledge is the definition given to the term discipline by most dictionaries. However, the etymology of the term discipline (from Latin "discipulus", student) suggests a close relation with education and the concept of disseminating that knowledge. A discipline is, ultimately, a set of theories and methods organized according to criteria that facilitates the teaching and learning process. The focus moves therefore from the solution of a problem, which is what supposedly triggers the learning process, to the transmission of knowledge (Russo Agrusti 1992).

Even if the categorization of knowledge into disciplines is very ancient, the sectorial approach 
to learning is a quite recent characteristic of our higher-education system, probably induced by the industry request of always higher level of specialization to keep up with the technological advancements of the last century. In the cathedral schools (educational institutions active in Europe since the early middle-age and precursors of modern universities) the teaching covered all 7 liberal arts in which the knowledge was organized at the time, i.e.: grammar, rhetoric, and logic (called "trivium"), plus arithmetic, geometry, music, and astronomy (called "quadrivium").

This multidisciplinary structure of education is similar to that one of primary and secondary schools at present times. Nevertheless, teaching different disciplines does not ensure that interconnections between the disciplines are highlighted or that students can benefit of an integration of different areas of knowledge, which the term interdisciplinary suggests instead. In order to clarify the meaning of the term and the different relations between disciplines in research and education, a brief taxonomy is presented below, according to the definitions first indicated by OECD in 1972 (OECD 1972) and more recently expanded and developed by several authors (Nicolescu 2002; Jacobs, Frickel 2009):

- Cross-disciplinary: term indicating the presence of a certain aspect or method in different disciplines. DeZure (1999) gives as example of this a reference to expressionism in literature during an art class on expressionism.

- Multidisciplinary: term indicating the juxtaposition of various disciplines, sometimes with no apparent connection between them. An example is represented by a school program that foresees education in music, mathematics, history.

- Pluridisciplinary: term indicating the juxtaposition of various disciplines with a certain degree of relation in the topic or in the scope. For example, the above mentioned arts of quadrivium were meant to give a representation of the discrete and continuous at rest and in motion.

- Interdisciplinary: term indicating an interaction among two or more different disciplines and an exchange of information or methods between the two, often with the aim of solving a common complex problem. An example of this can be the collaboration between a structural engineer and a fireman for developing a course on fire safety design of buildings.
- Transdisciplinary: term indicating the integration of methods and concepts of two or more disciplines into a common shared language and system of axioms, with the aim of developing a broader understanding and a holistic approach to problem solving (Nicolescu 2002). E.g. Piaget (1970) unified the knowledge beyond the disciplines of cognitive development and epistemology, now called genetic epistemology.

The definitions given above are qualitative definitions, where the grade of the intended interactions between disciplines may slightly vary depending on the context and the different authors. For example, cross-disciplinary is often used as an unspecific term indicating any kind of relations between disciplines, while pluridisciplinary is sometimes used as synonym of multidisciplinary. Jacobs and Frickel (2009) interpret the term interdisciplinary in a broader sense than Nicolescu (2002), while Dezure (1999) points out that the "term interdisciplinary is used variably as a concept, a methodology, a process, a way of knowing, and even a philosophy". Nevertheless, there is a central difference between multi-, inter-, and transdisciplinary, which is effectively explained by Choi and Pak ( 2006) by means of three adjectives, respectively: additive, interactive, and holistic.

A multidisciplinary approach can be sufficient for a problem that can be decomposed in a sequence of simpler problems solved by means of expertise in one discipline at a time. An example is a thermo-mechanic problem that can be decoupled in a thermal problem (e.g. the analysis of temperature of a beam exposed to a heat source) and in a subsequent mechanical problem (e.g. the calculation of the thermal expansion of the beam given by the temperature variation). If the problem cannot be decoupled (e.g. if the beam, expanding, gets closer to the heat source, so that the displacements depends on the temperatures and viceversa), an interaction between the two areas of knowledge is required, in order to develop a new procedure based on the theoretical tools of both thermodynamics and continuum mechanics for solving the uncoupled problem.

The close collaboration and interaction between experts of different disciplines is often sufficient for solving most specific problems and an interdisciplinary approach to problem-solving is therefore the focus of this study. However, there are cases where a broader perspective of the problem and innovative solutions can only be reached by availing a more holistic approach to learning 
that overcome the discipline boundaries. In the previous example a method is developed by interaction between two areas of knowledge, but the boundaries of the two single disciplines are not overcome. A more holistic approach to the problem would question the usual design procedure, where the beam is optimized for mechanical loads and then verified in presence of a heat source (such as e.g. a fire), and seek for a different design procedure capable of accounting both aspects in the design optimization. This could lead to a new and quite different shape of the constructive elements and, ultimately, to a novel construction technology. However, a pure holistic approach to problems that encompass several and very different disciplines may be very difficult and, in some cases, hinder the simplification of the problem into smaller and more understandable problems, which could have been instead obtained by following a reductionist approach.

\section{SURVEY}

In order to highlight the type and number of disciplines needed in disaster-resilience projects and their level of interaction, a survey has been undertaken by collecting information from all types of research and educational projects related to disaster resilience. Particular focus was given to the identification of problems in the interdisciplinary work, with the aim of getting insights on possible short- and long-term solutions for improving the development of disaster resilience projects and favour advances and innovation in the field.

The survey has been carried out by means of an online questionnaire, which has been distributed through the ANDROID Network. The choice of an online questionnaire has been favoured over other type of survey methods, for a twofold reason: from the point of view of the research, survey methods such as oral interviews and e-mail correspondence would have made more difficult to gather and analyse the data in an aggregated form, so that they could be analysed and presented in a statistical way, as well as archived in the online repository developed in the framework of the ANDROID project; from the perspective of the targeted respondents, who were all expected to be accustomed to work with computers and the internet, answering an online questionnaire was deemed the least timeconsuming method. The main drawback of online questionnaires is the limited availability to ask follow-up questions and gathering any additional information from the respondents. In order to ad- dress this drawback, the questionnaire included open-ended questions as a final item throughout the survey.

The questionnaire foresaw 24 different questions, conceptually divided in 4 main parts: i) an introductory part with 7 questions gathering general information on the project (name, leading institute, country, etc.); ii) a core part with 10 questions on the content and characteristics of the projects (topics, purpose, etc.); iii) a follow-up part with 2 questions focused on challenges of interdisciplinary work carried out during the project; iv) and a conclusive part with 8 questions aimed at indexing the project and the publications and reports produced.

The questions of the second and third part of the questionnaire are most relevant for the aim of this paper and are therefore presented and discussed in the next section. However, the complete list of the questions is reported as appendix of one of the ANDROID report (Faber et al. 2014), which can be freely downloaded from the Open Educational Research Platform of the ANDROD project (www.disaster-resilience.net/index.php/component/ oer/).

The questionnaire was online for ca. 6 months and gathered 57 answers from 55 different respondents (it was possible for a respondent to participate to the questionnaire with different projects). Since this number represents only a sample of the total number of European projects on disaster resilience, some statistical considerations on the survey outcomes were necessary for extrapolating more general conclusions on the interdisciplinary working in resilience related projects. The term interdisciplinary has been used in the questionnaire in its broader sense, in order to gather information on every type of collaboration and communication across different area of knowledge. However, the taxonomy presented in paragraph 2.4 has been kept in mind for the discussion of the results, where the effective level of interdisciplinary work in the projects described by the respondents was investigated.

\section{OUTCOMES OF THE QUESTIONNAIRE}

In the following, the outcomes of the questionnaire are presented, which refer to relevant aspects of the core and follow-up parts of the, and specifically: i) type of hazards considered in the projects; ii) categories of people and disciplines involved; iii) barriers encountered in interdisciplinary work and the actions taken to overcome them. 


\subsection{Natural and man-made hazards}

One of the central aspects of disaster resilience design concerns the selection of the hazards most relevant to study. This information also provides an indirect indication of the areas of knowledge and competence required to carry out the project. In particular, two distinct questions have been foreseen in the questionnaire, in order to identify the type of natural hazards (referred to as hazards in the physical environment in the questionnaire) and man-made hazards (referred to as hazards of human origin in the questionnaire) considered in current projects on disaster resilience. Since a single project can deal with several hazards, the respondents were allowed to select multiple answers to each of the two questions, among a set of pre-defined hazards indicated in the questionnaire. In case the hazard considered was not ascribable to any of the pre-defined categories, the answer "other" could be chosen and the hazard could be specified in a dedicated text box.

The following pre-defined categories for natural hazards were given: floods, wind storm (e.g. hurricane, snow, sand), heat wave, cold wave, earthquake, tsunami, volcano eruption, wild fire, and contamination (referred to natural causes, such as e.g. mercury contamination from geothermal areas and similar). As man-made hazards, the following broad types of hazards were distinguished: confrontation (e.g. conflict, war), financial crisis, malevolence (e.g. terrorism, cybercrime), health (e.g. pandemics), infrastructure breakdown, political riots, technological hazards (e.g. leakage of toxic substances). The distinction between natural and man-made hazard as presented in the questionnaire is quite simplistic, but has been adopted here in order to better clarify the pre-defined hazard categories in the questionnaire. Nevertheless, the authors recognize that many natural and climatic hazards in the last century are an indirect consequence of the human activity (Beck 1992) and a consistent, non-overlapping definition of natural and man-made hazards is hardly possible (Giddens 1990). This problem has been highlighted also by the answers of some respondents, which indicated sea level rise and climate changes in the field "other" of both type of hazards. For this reason, the answers to both questions are presented in an aggregated form in Figure 2a, where some additional categories were also included on the basis of hazards indicated by some respondents in the field "other" (drought, erosion, extreme precipitations, landslides, and sea level rise).

The most frequent natural disasters (highlighted with a blue shade in the histogram of Fig. 2a) are floods, reported in 34 of the 57 projects. The predominance of this hazard relates well with the indication given by the European Environmental Agency survey (EEA 2010) that indicate floods as the most costly disasters in Europe. The same report indicates that heat waves are responsible of the highest number of casualties. Nevertheless, the results of the questionnaires ranked heat waves only as fifth most studied natural hazards, after (floods, earthquakes, wind storms, and tsunami) and seventh most studied disaster if manmade hazards are also included. It is also interesting that few respondents indicated climate change hazards in the field "other". Such a hazard has not been considered as a separate category in the presentation of the results, as it is a very broad phenomenon that includes several of the hazards considered in the questionnaire. However, if the major hazards related to climate changes (such
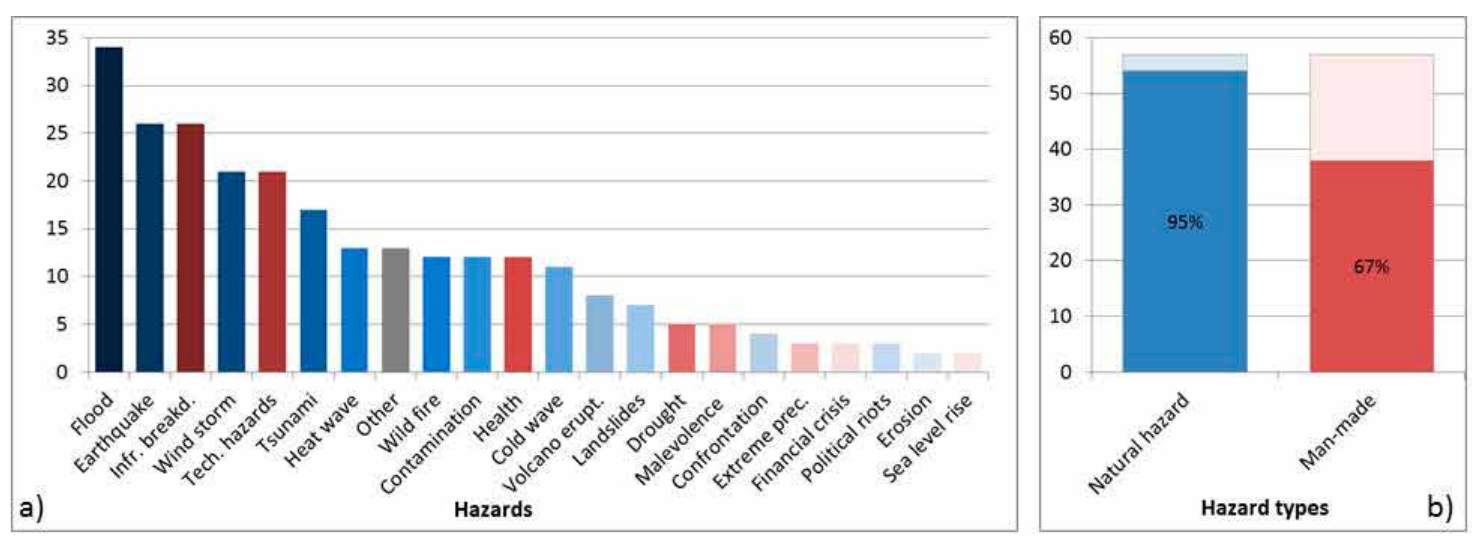

Fig. 2. Natural (blue shades) and man-made (red shades) hazards considered in the projects (a) and number of projects including natural and man-made hazards as a percentage of the total number of projects (b) 
as coastal erosion, drought, extreme precipitations, heat and cold waves, and sea level rise) are merged into one broad category, climate change is the most studied hazard, being present in 36 of the 57 projects.

Among man-made hazards (highlighted with a red shade in the histogram of Fig. 2a), the most frequent studied disaster reported by the respondents was infrastructural breakdowns, which appeared in 26 of the 57 projects, closely followed by technological hazards, reported instead in 21 of the 57 projects. The two hazards ranked respectively thirds and fifth among all natural and man-made hazards.

While only three projects did not indicate any natural hazards, man-made hazards were not considered in 19 of the 57 projects. This seems to indicate a predominance of natural hazards with respect to man-made hazards, which is observable in Figure 2b, where the percentages of 95\% to $64 \%$ refer to the number of projects where natural and man-made hazards were considered, with respect to the total number of projects participating in the questionnaire.

\subsection{Categories and disciplines}

Respondents were asked to indicate the different groups involved in the project by choosing from the following categories: academics, citizens, decision makers, stakeholders, opinion groups, volunteers, private enterprises, and others. The outcomes to this question are reported in Figure $3 \mathrm{a}$ and give an insight on the expertise and roles required in disaster resilience projects. By observing the figure, it is seen that academics are by far the professional figures most involved in the projects. However, this datum could be biased by the fact that the ques- tionnaire was distributed through the ANDROID network, which is mainly composed by academics. The results should therefore be regarded more as indicative of a significant numbers of different professions involved in resilience-related projects, as suggested by the fact that all categories were indicated by at least 10 respondents.

Figure 4a shows instead the results related to the different areas of expertise of the people involved in the projects. In an attempt of cover all possible areas of expertise, 24 different disciplines have been indicated as possible answers to the question, according to the classification of disciplines proposed by the Simple Knowledge Organization System of UNESCO (SKOS 2009), to which the field "other" was added, in order to include other possible disciplines that the respondents could not identify in the given categories. The SKOS nomenclature has been preferred over other classification systems available in literature (Kumbhar 2012) because it is a Semantic Web standard (W3C) recommendation (Backer et al. 2013) and therefore most suitable to support the data sharing envisaged by the inclusion of the survey results in the online repository of ANDROID and to allow potential future expansions of the study.

The analysis of the answers (Fig. 4a) shows that Technological Science (referred as technology in the figure), Geography, Earth and Space Science (abbreviated as Earth \& Space), and Sociology are the most required area of expertise in resilience-related projects. Furthermore, all disciplines indicated according to the SKOS classification are represented in at least one project, with the sole exception of astrophysics. In addition to the pre-defined categories, additional areas of expertise were indicated in the field "other" by 18
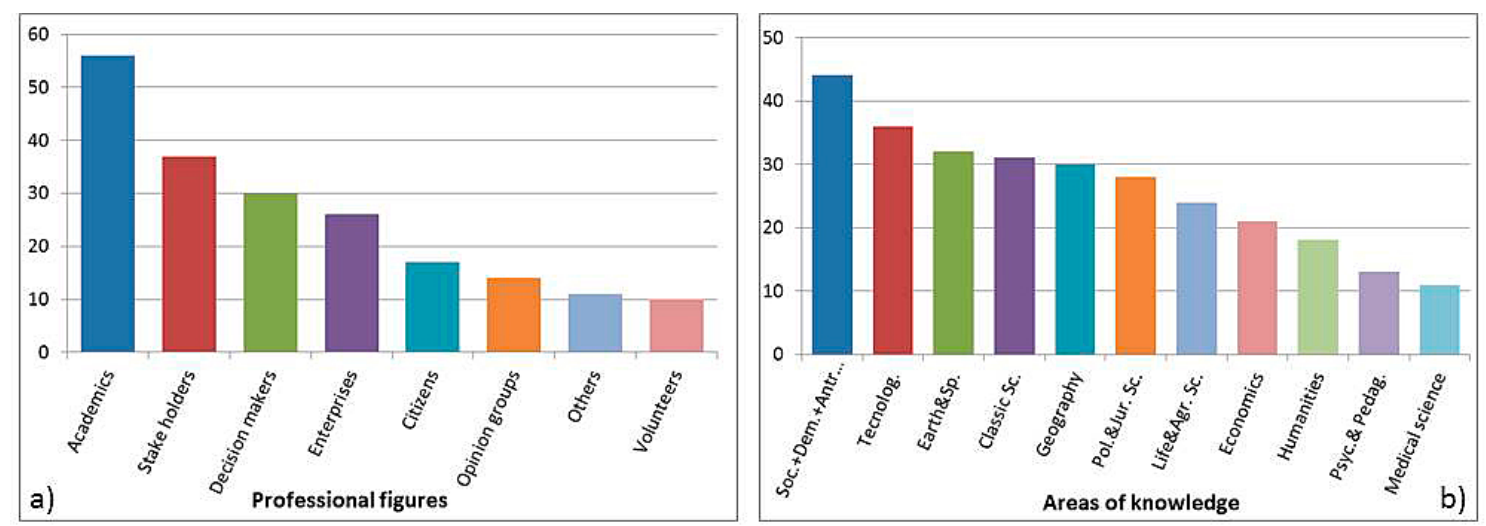

Fig. 3. No. of projects involving different categories of people (a) and different areas of knowledge (b) 

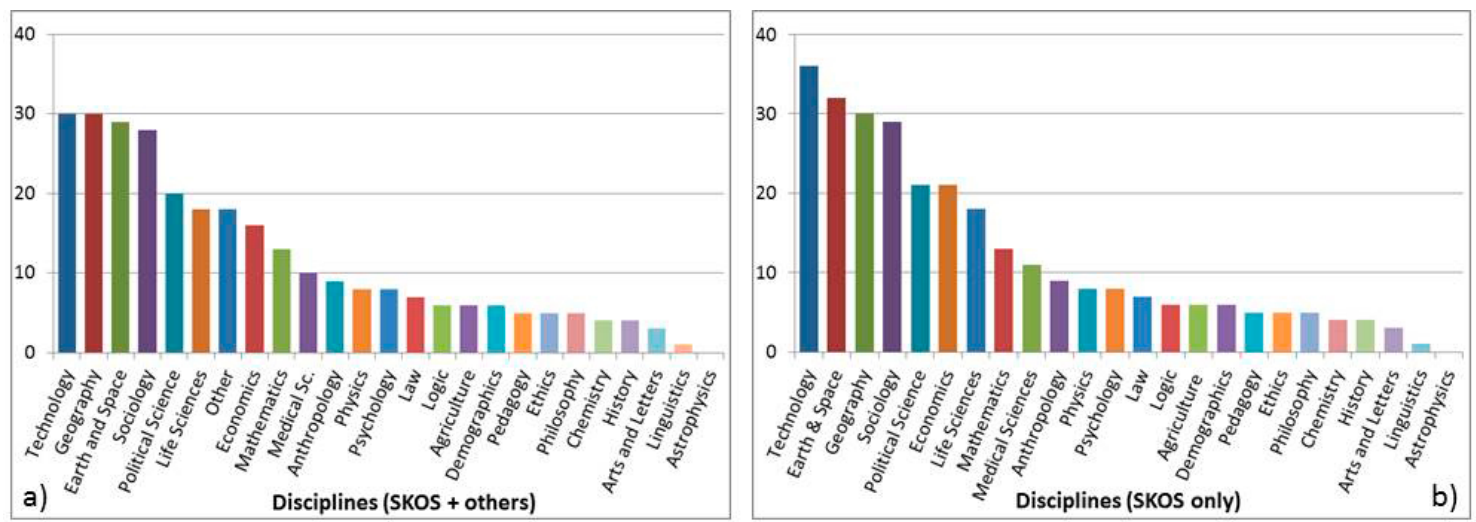

Fig. 4. No. of projects involving a discipline as answered by respondents (a) and as after a redistribution of the category "other" (b)
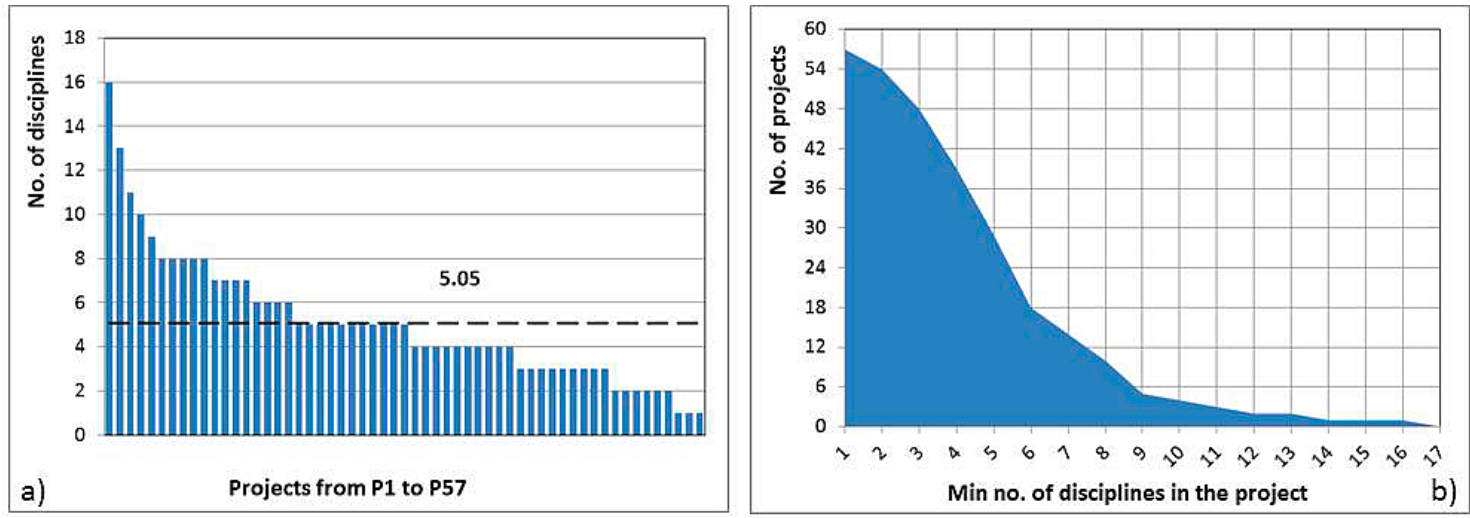

Fig. 5. Frequency (a) and cumulative frequency (b) of the number of disciplines involved in a single project (the dotted black line in the left chart a) indicates the average number of disciplines)

respondents and included geology, urban planning, risk management, disaster management, climate science, architecture and civil engineering, and others. Nevertheless, all disciplines additionally specified in the field "other" seemed to refer to one or more of the SKOS categories indicated in the questionnaire: e.g. climate science is a part of earth and space science; likewise, urban planning, architecture, and civil engineering are part of Technology; while risk and disaster management encompasses several disciplines, such as Technology, Economical Science (referred to as Economics in the following), and Earth \& Space. In some cases, the associated disciplines had already been indicated by the respondent and should therefore be interpreted as an attempt of giving a more detailed specification of the topics treated within the indicated disciplines than as an indication of a distinct discipline. In other cases, the respondent failed to identify the appropriate branch, as intended by the SKOS system. If the disciplines indicated in the field other are redistributed into the appropriate categories (when not already indicated), the distribution of the disciplines in the projects looks as shown in Figure $4 \mathrm{~b}$. Even if the most frequent discipline remains Technology, the second and third disciplines, namely Geography and Earth \& Space, have here an inverted position. The same inversion can be observed between Life Science and Economics, which occupied the fifth and sixth position. Even though the total number of answers (288) was, as expected, significantly higher that the number of pre-defined categories, a bias in the representativeness of the results could be argued, as a consequence of a non-homogenous broadness of the disciplines classified according to the SKOS system. For example, a disciplines like Technological Science encompasses several branches of engineering (structural, environmental, transport, mechanical, chemical, etc.) as well as computer science, architecture, and urban planning; on the contrary, disciplines such as Logic, Astrophysics, and Linguistics are commonly considered as branches of other disciplines (namely, mathematics, physics, and letters, respectively). 
Being pertinent to a more limited area of knowledge, the latter disciplines could have an intrinsic lower probability of occurrence in the projects than other disciplines such as technology or earth and space. For this reason, an attempt has been made to group together disciplines that require a similar background or pertains to the same area of knowledge, in order to have fewer more homogenous categories. The faculties or study program of several universities has been considered as basis for the grouping of the disciplines and the following alternative categorization of the disciplines has been defined:

- The disciplines of mathematics, logic, physics, astrophysics, and chemistry, have been grouped together in a category named classical sciences, following the classification used in the past by most academic faculties;

- Similarly, the disciplines of art and letters, linguistic, history, philosophy, and ethics, have been grouped into one broader category and referred to as humanities, term still used in most universities and high educational institutes to indicate these disciplines;

- The disciplines of sociology, demography and anthropology have been included in a broader category that refers to the study of primitive and modern societies;

- The disciplines of political science and juridical science, having similar background and end-markets, have been merged in one single category;

- The discipline of life science and agricultural science have been merged in one category for similar reasons;

- The same has been done for the disciplines of psychology and pedagogy;

- All other disciplines not mentioned here has been left unchanged as single categories.

The results obtained rearranging the answers according to this alternative classification are reported in Figure $3 \mathrm{~b}$ and show a slight predominance of the social disciplines (namely Sociology, Demography, and Anthropology) over the technological disciplines. The results discussed above are related to the frequency of each discipline or area of knowledge in disaster resilience projects and can give an indication of the most relevant area of expertise required to tackle such problems. However, if the level of interdisciplinary work required in such projects is of interest, attention should be also paid to the number of different disciplines involved in the same the project. This can be observed in Figure 5a, where the most frequent value (mode) of disciplines involved in one single project (5) is also reported. The data reported here and below refer to the categorizations of disciplines according to SKOS, where the answers indicated in the field "other" has been redistributed into the appropriate categories (cf. Fig. 4b).

Figure $5 \mathrm{~b}$ shows instead the cumulative frequency of the number of disciplines in each project. By looking at the figure, the following data can be observed: i) a minimum of 5 different disciplines has been reported in 29 projects out of 57 ; ii) the maximum number of disciplines in a project corresponds to 16 and has been reported by one project only; iii) the minimum number of disciplines, i.e. 1 , has been reported by three projects, meaning that no interdisciplinary work was in facts present in 3 out of 57 projects.

The information provided above gives an overview of the level of interdisciplinary work present in the various projects, disregarding in this graphic the type and distance of the areas of knowledge interacting with one another. In order to appreciate this aspect, an incidence matrix is shown in Figure 6, where the number of concomitant occurrence of two disciplines (indicated in the labels of the respective row and column of the cell) can be observed outside the diagonal. By looking at the darker cells, which highlight the highest concomitant occurrences between two disciplines, the following can be observed:

- Earth and Space and Geography have the highest level of concomitant occurrence, being present simultaneously in 23 out of 57 projects.

- Geography seems also to have a close relationship with Sociology (18 simultaneous occurrences), Technology (17), Life Science, and Political Science (15).

- Other tight interconnections between disciplines can be observed between Technology and Earth and Space (18 simultaneous occurrence), Economy (16), and Sociology (15).

These data provide useful information on the level of interrelation between disciplines and help identifying the most important area of knowledge needed for resilience-based design.

\subsection{Barriers to interdisciplinary work}

Two different questions have been asked on the barriers encountered in interdisciplinary work: a first multiple-choice question, where the respondents should select one or more barriers among those indicated; and an additional, non-mandatory question on the actions undertaken to overcome the barriers encountered, where the respondents 


\begin{tabular}{|c|c|c|c|c|c|c|c|c|c|c|c|c|c|c|c|c|c|c|c|c|c|c|c|c|}
\hline & : & 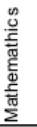 & 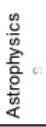 & 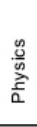 & 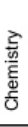 & $\begin{array}{l}\dot{\mathscr{D}} \\
\stackrel{Ð}{ \pm}\end{array}$ & 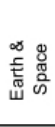 & 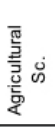 & 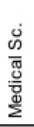 & $\begin{array}{l}\text { के } \\
\text { 응 } \\
\text { 등 } \\
\text { 잉 }\end{array}$ & $\begin{array}{l}\text { के } \\
\frac{0}{8} \\
\frac{2}{2} \\
\frac{c}{\frac{1}{2}} \\
\frac{5}{4}\end{array}$ & 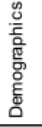 & 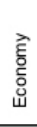 & 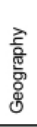 & $\frac{\text { Z्̀ }}{\frac{\underline{w}}{I}}$ & 胥 & 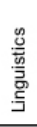 & 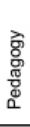 & 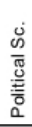 & $\begin{array}{l}\text { के } \\
\text { o응 } \\
\frac{0}{0} \\
\text { के } \\
0\end{array}$ & 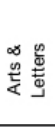 & 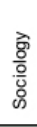 & 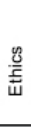 & 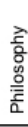 \\
\hline Logic & 6 & 5 & 0 & 0 & 1 & 3 & 4 & 1 & 1 & 6 & 3 & 2 & 4 & 4 & 1 & 0 & 1 & 1 & 1 & 1 & 0 & 5 & 1 & 0 \\
\hline Mathemathics & 5 & 13 & 0 & 2 & 1 & 5 & 6 & 1 & 3 & 10 & 3 & 3 & 5 & 9 & 1 & 0 & 1 & 2 & 3 & 2 & 0 & 7 & 1 & 0 \\
\hline Astrophysics & 0 & 0 & 0 & 0 & 0 & 0 & 0 & 0 & 0 & 0 & 0 & 0 & 0 & 0 & 0 & 0 & 0 & 0 & 0 & 0 & 0 & 0 & 0 & 0 \\
\hline Physics & 0 & 2 & 0 & 8 & 2 & 5 & 7 & 2 & 1 & 4 & 1 & 3 & 4 & 7 & 2 & 1 & 0 & 1 & 5 & 2 & 1 & 3 & 2 & 1 \\
\hline Chemistry & 1 & 1 & 0 & 2 & 4 & 4 & 3 & 2 & 1 & 3 & 1 & 2 & 2 & 3 & 2 & 0 & 0 & 1 & 1 & 0 & 0 & 2 & 1 & 0 \\
\hline Life Sc. & 3 & 5 & 0 & 5 & 4 & 18 & 15 & 6 & 5 & 10 & 3 & 6 & 10 & 15 & 4 & 3 & 0 & 2 & 8 & 3 & 1 & 11 & 2 & 0 \\
\hline Earth \& Space & 4 & 6 & 0 & 7 & 3 & 15 & 32 & 4 & 4 & 18 & 4 & 6 & 14 & 23 & 3 & 4 & 0 & 1 & 13 & 4 & 1 & 14 & 1 & 1 \\
\hline Agricultural $\mathrm{Sc}$. & 1 & 1 & 0 & 2 & 2 & 6 & 4 & 6 & 2 & 5 & 3 & 3 & 5 & 5 & 4 & 3 & 0 & 0 & 3 & 1 & 1 & 4 & 1 & 0 \\
\hline Medical Sc. & 1 & 3 & 0 & 1 & 1 & 5 & 4 & 2 & 11 & 9 & 1 & 1 & 3 & 4 & 0 & 3 & 0 & 3 & 3 & 4 & 0 & 5 & 1 & 1 \\
\hline Technology & 6 & 10 & 0 & 4 & 3 & 10 & 18 & 5 & 9 & 35 & 5 & 4 & 16 & 17 & 3 & 4 & 1 & 3 & 11 & 4 & 2 & 15 & 3 & 1 \\
\hline Anthropology & 3 & 3 & 0 & 1 & 1 & 3 & 4 & 3 & 1 & 5 & 9 & 2 & 4 & 5 & 3 & 1 & 1 & 1 & 5 & 4 & 1 & 8 & 3 & 2 \\
\hline Demographics & 2 & 3 & 0 & 3 & 2 & 6 & 6 & 3 & 1 & 4 & 2 & 6 & 3 & 6 & 3 & 1 & 0 & 1 & 3 & 1 & 1 & 5 & 1 & 0 \\
\hline Economy & 4 & 5 & 0 & 4 & 2 & 10 & 14 & 5 & 3 & 16 & 4 & 3 & 21 & 14 & 4 & 3 & 0 & 1 & 10 & 4 & 1 & 11 & 1 & 1 \\
\hline Geography & 4 & 9 & 0 & 7 & 3 & 15 & 23 & 5 & 4 & 17 & 5 & 6 & 14 & 30 & 4 & 5 & 0 & 1 & 15 & 4 & 1 & 18 & 1 & 1 \\
\hline History & 1 & 1 & 0 & 2 & 2 & 4 & 3 & 4 & 0 & 3 & 3 & 3 & 4 & 4 & 4 & 1 & 0 & 0 & 3 & 1 & 1 & 3 & 1 & 0 \\
\hline Law & 0 & 0 & 0 & 1 & 0 & 3 & 4 & 3 & 3 & 4 & 1 & 1 & 3 & 5 & 1 & 7 & 0 & 0 & 4 & 1 & 1 & 6 & 1 & 0 \\
\hline Linguistics & 1 & 1 & 0 & 0 & 0 & 0 & 0 & 0 & 0 & 1 & 1 & 0 & 0 & 0 & 0 & 0 & 1 & 0 & 0 & 0 & 0 & 1 & 1 & 0 \\
\hline Pedagogy & 1 & 2 & 0 & 1 & 1 & 2 & 1 & 0 & 3 & 3 & 1 & 1 & 1 & 1 & 0 & 0 & 0 & 5 & 0 & 2 & 0 & 2 & 1 & 1 \\
\hline Political Sc. & 1 & 3 & 0 & 5 & 1 & 8 & 13 & 3 & 3 & 11 & 5 & 3 & 10 & 15 & 3 & 4 & 0 & 0 & 21 & 4 & 2 & 12 & 3 & 3 \\
\hline Psychology & 1 & 2 & 0 & 2 & 0 & 3 & 4 & 1 & 4 & 4 & 4 & 1 & 4 & 4 & 1 & 1 & 0 & 2 & 4 & 8 & 1 & 5 & 1 & 1 \\
\hline Arts \& Letters & 0 & 0 & 0 & 1 & 0 & 1 & 1 & 1 & 0 & 2 & 1 & 1 & 1 & 1 & 1 & 1 & 0 & 0 & 2 & 1 & 3 & 2 & 2 & 1 \\
\hline Sociology & 5 & 7 & 0 & 3 & 2 & 11 & 14 & 4 & 5 & 15 & 8 & 5 & 11 & 18 & 3 & 6 & 1 & 2 & 12 & 5 & 2 & 29 & 4 & 4 \\
\hline Ethics & 1 & 1 & 0 & 2 & 1 & 2 & 1 & 1 & 1 & 3 & 3 & 1 & 1 & 1 & 1 & 1 & 1 & 1 & 3 & 1 & 2 & 4 & 5 & 2 \\
\hline Philosophy & 0 & 0 & 0 & 1 & 0 & 0 & 1 & 0 & 1 & 1 & 2 & 0 & 1 & 1 & 0 & 0 & 0 & 1 & 3 & 1 & 1 & 4 & 2 & 5 \\
\hline
\end{tabular}

Fig. 6. Incidence matrix of the different disciplines: higher numbers (darker shading) outside the diagonal indicate a higher occurrence of the two disciplines (row and column) in the same project

could answer freely, by writing a short comment in a textbox.

A first analysis of the results shows that, while problems related to interdisciplinary work have been reported in more than $90 \%$ of the projects, countermeasures were taken in less than three quarter of the projects. This could either indicate a limited understanding of the core of the problem, or an intrinsic difficulty in finding solutions for the problem. The two histograms shown in Figure 7 provide more information in this respect.

The histogram in Figure $7 \mathrm{a}$ shows that the main barrier to interdisciplinary work is the presence of different conceptual frameworks, issue that has been reported in more than half of the projects. Different methodologies and conflicting terminologies closely follow in term of frequency of occurrence in the projects. Lack of resources, different work practice, and communication barriers were indicated in ca. one third of the projects. Administrative obstacles and access to people are less common problems, even if present in ca. one sixth of the projects. Very few projects indicated instead the problem of contrasting techniques as barrier encountered during the interdisciplinary work. This may seem strange, considering the relevance of other barriers such as different method- ologies and practices. Nevertheless, even if related, the three terms "methodologies", "practices", and "techniques" have different acceptations, in that they highlight a more theoretical, or experimental/ pragmatic, or applicative approach, respectively. For this reason they have been presented as separate categories in the questionnaire and the higher frequency of different methodologies and practices over contrasting technique has been interpreted as an indication of differences in the approach to problem-solving that are of more scientific rather than just technical nature. Few additional barriers were also specified in the field "other", such as: conflicting objectives, lack of interest in interdisciplinary work, limited access to data, limited time.

The answers to the second questions were organized utilizing a few common countermeasures that were identified by reading the comments indicated by most respondents. The results of this analysis, which is however subjected to interpretation, are shown in Figure 7b. The histograms reports the absolute frequency of the categories ordered according a criterion of similarities between the main aims of the countermeasures. By looking at the figure, it can be observed that, in the vast majority of the projects, problems in interdisciplinary work have been overcome by means of meet- 

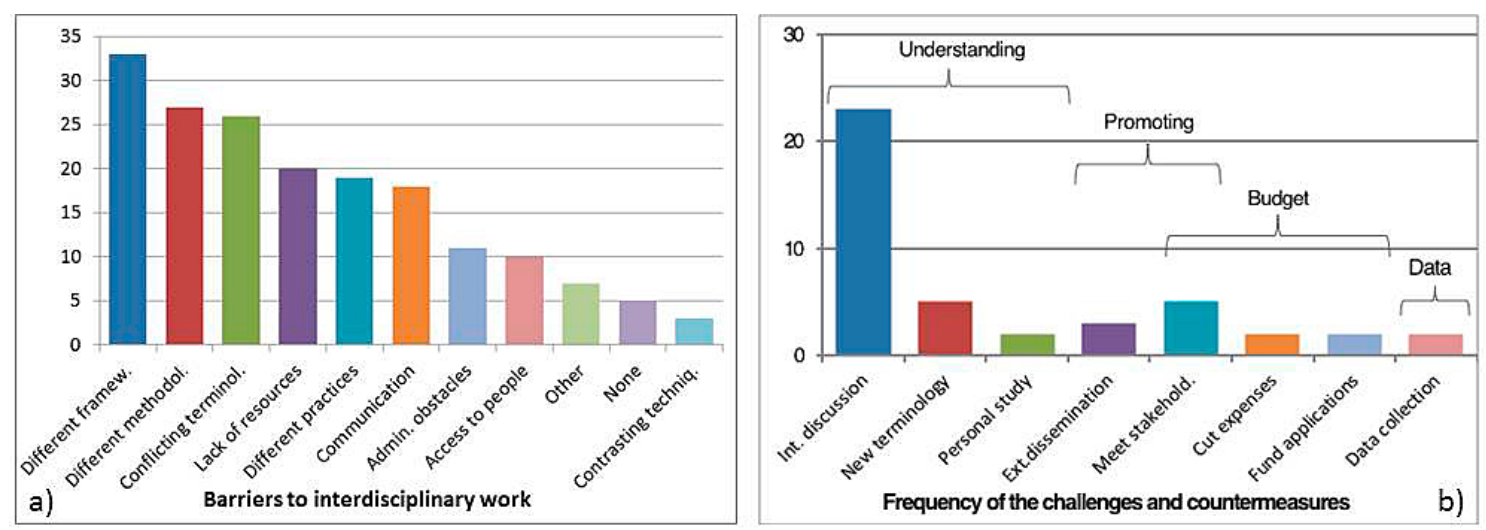

Fig. 7. Barriers in disaster resilience projects in descent order of frequency (a) and actions undertaken to solve them (b), organized in macro-categories aimed at solving problems of: understanding (60\%); promotion (26\%); budget (19\%); lack of data (4\%)

ing and discussion among the project participants. This result seems consistent with the outcomes of the first question, where the high number of projects reporting problems related to differences in the framework, methods and terminology could suggest a general problem of understanding among different disciplines. Other countermeasures that seem oriented to favour a better understanding among experts of different areas are the definition of a new terminology and personal study aimed at expanding individual knowledge in other areas. If these answers are grouped together, measures aimed at solving problems related to lack of understanding were undertaken in $61 \%$ of the project. Similarly, other macro-categories can be defined by grouping countermeasures that seem aimed at the same purpose. Specifically, measures aimed at overcoming budget problems and at promoting the results of the projects were undertaken by $19 \%$ and $16 \%$ of the projects, respectively, while measures aimed at solving problems related to lack of data were reported by $4 \%$ of the project.

\section{CONCLUSION}

The survey described in this paper represents one of the first attempts to collect data on the state of art and practice on interdisciplinary work on resilience to natural and man-made disaster. The review of the answers to the questionnaire has highlighted the following main aspects of disaster resilience projects:

- Natural hazards (and in particular floods and extreme temperature events) seem to be more studied than man-made hazard in current disaster resilience projects. This relates well with the fact that natural hazards are more frequent than man-made hazard and have typically a higher number of casualties (even though, contrarily to most natural hazards, technological accidents may have strong repercussion on the environment).

- Projects on disaster resilience include 5 different disciplines as an average. Technology, earth and space, geography, and sociology are the most frequent disciplines, which highlights the importance of both technological and social aspects in disaster resilience design.

- Geography is associated to Earth and Space and Sociology in most projects, which suggests that, covering technical and socio-political aspects may work as a bridge discipline between technical and social disciplines.

- Despite the important role played by regulations and policy on the prevention of disasters and the recovery of the society in the aftermath of a disaster, juridical disciplines are poorly represented in current projects.

- The lack of a common framework and terminology represents a major barrier to interdisciplinary work.

The associations found between several disciplines indicate that information and methods pertaining to different disciplines are exchanged in most problems. However, the barriers to the interdisciplinary work highlighted by most respondents indicate that a full integration of associated disciplines into a common shared language and system of axioms, i.e. a transdisciplinary approach, according to the taxonomy presented in par. 2.4, is missing. In order to achieve a higher level of integration between disciplines, short-term solution such as the ones indicated by the respondents (more meetings, discussions, etc.) may not be sufficient. A consist- 
ent organization of terms and knowledge related to disaster resilience should be established primarily within educational institutes, since research papers and other dissemination means rarely address a very broad public in different fields. The establishment of such education would favour the development of resilience-based design as a discipline with its own framework of knowledge and terminology and enhance the design approach from an interdisciplinary level to a transdisciplinary one. For this aim, efforts on development of new courses and establishment of new education lines are required from universities and HEIs. In this respect, the incidence matrix reported in Figure 6 may represent a useful tool for selecting the most important areas of knowledge to be included in such educational programs.

\section{ACKNOWLEDGMENTS}

The financial support of the Lifelong Learning Programme of the European Union is gratefully acknowledged, as well as the scientific contribution of all WP4 members of the ANDROID Disaster Resilience Network.

\section{REFERENCES}

Adger, W. 2003. Social capital, collective action and adaptation to climate change, Economic Geography 79(4): 287-404. http://dx.doi. org/10.1111/j.1944-8287.2003.tb00220.x

ANDROID. 2011. ANDROID Disaster Resilience Network [online]. Available at: http://www.disaster-resilience.net/index.php [accessed May 2014]

Auf der Heide, E. 2004. Common misconceptions about disasters: panic, the "disaster syndrome" and looting, in The first 72 hours: a community approach to disaster preparedness. New York, US: Ed. Margaret O'Leary.

Augusti, G.; Borri, C.; Niemann, H. 2001. Is Aeolian risk as significant as other environmental risk?, $R e$ liability Engineeing \& System Safety 74(3): 227-237. http://dx.doi.org/10.1016/S0951-8320(01)00077-1

Backer, T.; Bechhofer, S.; Isaac, A.; Miles, A.; Schreiber, G.; Summers, E. 2013. Key choices in the design of simple knowledge organization system (SKOS), WebSemantics: Science, Services and Agents on the World Wide Web 20: 35-49.

http://dx.doi.org/10.1016/j.websem.2013.05.001

Beck, U. 1992. Risk society, towards a new modernity. London: Sage Publications.

Bhamra, R.; Dani, S.; Burnard, K. 2011. Resilience: the concept, a literature review and future directions, International Journal of Production Research 49(18): 5375-5393.

http://dx.doi.org/10.1080/00207543.2011.563826
Biondini, F.; Frangopol, D. R. S. 2008. On structural robustness, redundancy, and static indeterminacy. Vancouver, CA, Structures Congress 2008: Crossing Borders. http://dx.doi.org/10.1061/41016(314)237

Bonanno, G.; Galea, S.; Bucciareli, A.; Vlahov, D. 2007. What predicts psychological resilience after disaster? The role of demographics, resources, and life stress, Journal of Consulting and Clinical Psychology 75(5): 671-682.

http://dx.doi.org/10.1037/0022-006X.75.5.671

Bruneau, M.; Chang, S. E.; Eguchi, R. T.; Lee, G. C.; O'Rourke, T. D.; Reinhorn, A. M.; Shinozuka, M.; Tierney, K.; Wallace, W. A.; von Winterfeldt, D. 2003. A framework to quantitatively assess and enhance the seismic resilience of communities, Earthquake Spectra 19(4): 733-752.

http://dx.doi.org/10.1193/1.1623497

Cadell, S.; Karabanow, J.; Sanchez, M. 2001. Community, empowerment, and resilience: paths to wellness, Canadian Journal of Community Mental Health 20: 21-36. http://dx.doi.org/10.7870/cjcmh-2001-0002

Chamlee-Wright, E. 2010. The cultural and political economy of recovery: social learning in a post-disaster environment. New York: Routledge.

Chang, S.; Shinozuka, M. 2004. Measuring improvements in the disaster resilience of communities, Earthquake Spectra 20(3): 739-755. http://dx.doi.org/10.1193/1.1775796

Choi, B.; Pak, A. 2006. Multidisciplinarity, interdisciplinarity, and transdisciplinarity in health research, services, education and policy: 1. Definitions, objectives, and evidence of effectiveness, Clinical and Investigative Medicine 29(6): 351-364.

Choularton, R. 2001. Complex learning: organizational learning from disasters, Safety Science 39(1-2): 61-70. http://dx.doi.org/10.1016/S09257535(01)00026-1

Cimellaro, G.; Reinhorn, A.; Bruneau, M. 2010. Framework for analytical quantification of disaster resilience, Engineering Structures 32(11): 3639-3649. http://dx.doi.org/10.1016/j.engstruct.2010.08.008

DeZure, D. 1999. Interdisciplinary teaching and learning, Teaching Excellence - Toward the Best in the Academy 10(3): 1998-1999.

EEA. 2010. Mapping the impacts of natural hazards and technological accidents in Europe - An overview of the last decade. Luxembourg: European Environment Agency - Publication office of te European Union.

Faber, M. 2006. Robustness of structures: an introduction, Structural Engineering International 16(2): 101-101. http://dx.doi.org/10.2749/101686606777962404

Faber, M.; Nishijima, K.; Giuliani, L.; Revez, A.; Mendes, J.; Sparf, J.; Jayasena, S.; Bucx, T. 2014. Good practice review of interdisciplinary working in disaster resilience education, Salford, UK: ANDROID Resiliece Network - Life Long Learning Programme of the European Union.

Giddens, A. 1990. Consequences of modernity. Cambridge: Polity Press. 
Gilbert, S. 2010. Disaster resilience: a guide to the literature. NIST Special Publication 1117. Gaithersburg: National Institute of Standards and Technology Building and Fire Research Laboratory. http://dx.doi.org/10.6028/nist.sp.1117

Hamel, G.; Valikangas, L. 2003. The quest for resilience, Harvard Business Review 81(9): 52-65.

Hollnagel, E.; Woods, D.; Leveson, N. 2006. Resilience engineering: concepts and precepts. Aldershot: Ashgate.

Haas, J.; Kates, R.; Bowden, M. 1977. Reconstruction following disaster. Cambridge: MIT Press.

Jacobs, J.; Frickel, S. 2009. Interdisciplinarity: a critical assessment, Annual Review of Sociology 35: 43-65. http://dx.doi.org/10.1146/annurevsoc-070308-115954

JCSS. 2008. Risk assessment in engineering - principles, system representation, and risk criteria. Joint Commitee on Structural Safety.

Keck, M.; Sakdalpolrak, P. 2013. What is social resilience? Lessons learned and way forward, Erdkunde 67(1): 5-19. http://dx.doi.org/10.3112/erdkunde.2013.01.02

Kumbhar, R. 2012. Library classification trends in the 21st century. Suffolk: CP Chandos Publishing. http://dx.doi.org/10.1533/9781780632988

Nicolescu, B. 2002. Manifesto of transdisciplinarity (translation from French by Karen-Claire Voss). New York.

Norris, F. H.; Stevens, S. P.; Pfefferbaum, B.; Wyche, K. F.; Pfefferbaum, R. L. 2008. Community resilience as methafor, theory, set of capabilities, and strategy for disaster readiness, American Journal of Community Psychology 4(1-2): 127-150. http://dx.doi.org/10.1007/s10464-007-9156-6

OECD. 1972. Interdisciplinarity: problems of teaching and research in universities. Paris: Organization of Economic Cooperation and Development (OECD).

Ortensi, M.; Petrini, F.; Bontempi, F.; Giuliani, L. 2013. RISE: a method for the design of resilient infrastructures and structures against emergencies, in Proceedings of the $11^{\text {th }}$ International Conference on Structural Safety and Reliability, ICOSSAR 2013, 16-20 June 2013, New York, USA, 605-612.

Paton, D.; Johnston, D. 2006. Disaster resilience: an integrated approach. Springfield: Charles C. Thomas Publications Ltd.

Pelling, M. 2007. Learning from others: the scope and challenges for participatory disaster risk assessment,
Disasters 31(4): 373-385. http://dx.doi.org/10.1111/ j.1467-7717.2007.01014.x

Pescaroli, G.; David, A. D. 2015. A definition of cascading disasters and cascading effects: going beyond the "toppling dominos" metaphor, Planet@Risk 3(1): 58-67.

Piaget, J. 1970. Genetic epistemology. New York: W.W. Norton \& Company.

Quarantelli, E. 1994. Looting and antisocial behavior in disasters. Preliminary Paper no. 205. University of Delaware: Disaster Research Center.

Rasmussen, B.; Allen, S.; Rasmussen, Z. A.; Bajwa, R. 2013. Learning from disasters to save lives every day in Pakistan, The Lancet 381(9885): 2232-2234. http://dx.doi.org/10.1016/S0140-6736(13)60652-2

Renschler, C. S.; Frazier, A. E.; Arendt, L. A.; Cimellaro, G. P.; Reinhorn, A. M.; Bruneau, M. 2010. Developing the 'PEOPLES' resilience framework for defining and measuring disaster resilience at the community scale, in Proceedings of the $9^{\text {th }}$ U.S. National and $10^{\text {th }}$ Canadian conference on Earthquake Engineering, 25-29 July 2010, Toronto, Ontario, Canada. Paper No. 1827, 1-10.

Russo Agrusti, T. 1992. Conoscere l'insegnamento - matriali per la formazione degli insegnanti. Firenze: La Nuova Italia.

Sheffi, Y. 2005. Building a resilient supply chain, Harvard Business Review Supply Chain Strategy 1(8): $1-4$.

SKOS. 2009. SKOS Simple Knowledge Organization System - W3C recommendation, in Miles, A.; Bechhofer, S. (Eds.). W3C.

Starrosek, U. 2009. Progressive collapse of structures. London: Thomas Telford Publishing. http://dx.doi. org/10.1680/pcos.36109

Ullberg, S. 2013. Watermarks. Urban flooding and memoryscape in Argentina. Doctoral thesis. Stockholm: Acta Universitatis Stockholmiensis.

UNDP. 2013. Community based resilience assessment (CoBRA) conceptual framework and methodologies. UNDP Drylands Development Centere - Disaster Risk Reduction Action Plan (DRRAP).

Walker, B.; Holling, C.; Carpenter, S.; Kinzig, A. 2004. Resilience, adaptability and transformability in social-ecological systems, Ecology and Society 9(2): 5[online]. Available at: http://www.ecologyandsociety.org/vol9/iss2/art5/ 